\title{
SEMIOLOGIA CARDIOVASCULAR: INSPEÇÃO, PALPAÇÃO E PERCUSSÃO
}

\author{
CARDIOVASCULAR EXAMINATION: INSPECTION, PALPATIONAND PERCUSSION
}

Antônio Pazin-Filho; André Schmidt \& Benedito Carlos Maciel

Docentes. Departamento de Clínica Médica. Faculdade de Medicina de Ribeirão Preto - USP

CoRRESPONDÊnCIA: Antônio Pazin-Filho - R. Bernardino de Campus, 1000, CEP: 14015-030, Ribeirão Preto - SP. e-mail: apazin@fmrp.usp.br

PAZIN-FILHO A; SCHMIDT A \& MACIEL BC. Semiologia cardiovascular: Inspeção, palpação e percussão. Medicina, Ribeirão Preto, v. 37: 227-239, jul./dez. 2004.

RESUMO: A importância da avaliação da inspeção e da palpação do sistema cardiovascular é ressaltada. Procurou-se demonstrar a importância da interpretação dos dados obtidos na análise do ictus cordis, da perfusão periférica e dos pulsos arteriais e venosos para as diversas cardiopatias, sempre com o objetivo de sistematização.

UNITERMOS: Sistema Cardiovascular. Semiologia. Pulso Arterial.

\section{1- INTRODUÇÃO}

Dentre as técnicas disponíveis para o exame físico do sistema cardiovascular, a ausculta cardíaca, em face da complexidade que se associa às múltiplas peculiaridades de sua adequada utilização, representa um desafio para o iniciante. A complexidade aliada ao fascínio que o método exerce sobre aqueles que iniciam o treinamento em semiologia cardiovascular acaba por ofuscar, em certa medida, a valorização dos demais métodos de investigação semiológica, que podem ser empregados e que são extremamente valiosos. Claro está que, na dependência do sistema avaliado, uma ou outra das técnicas existentes para sua investigação (inspeção, palpação, percussão ou ausculta) pode ser preponderante sobre as demais. É o que ocorre com a abordagem semiológica do sistema cardiovascular, em que a técnica de percussão tem valor limitado, quando comparada com as demais. Por outro lado, a inspeção e a palpação oferecem informações extremamente relevantes, que complementam aquelas obtidas com a ausculta, para a constituição do conjunto de dados clí- nicos, que dão substrato ao diagnóstico das diferentes doenças cardiovasculares.

Pretende-se, nesta revisão, discutir, de modo sistemático, as técnicas semiológicas, consolidadas pela prática clínica, para avaliação do sistema cardiovascular, com o objetivo primário de oferecer, principalmente ao estudante que inicia o treinamento em semiologia médica, uma base sólida e consistente, fundamentada em correlações entre aspectos fisiopatológicos e elementos de ordem clínica.

A discussão desses conceitos será dividida em cinco tópicos: ictus cordis, perfusão periférica, pulsos arteriais, pulsos venosos e percussão do precórdio.

\section{2- ICTUS CORDIS}

O ictus cordis, também conhecido como impulso apical ou choque da ponta, traduz o contato da porção anterior do ventrículo esquerdo com a parede torácica, durante a fase de contração isovolumétrica, do ciclo cardíaco. Embora os termos "impulso apical" e "choque da ponta" sejam comumente utilizados para 
denominar o ictus cordis, não se trata, realmente, da ponta do coração em contato com a parede torácica. $\mathrm{Na}$ verdade, o ápice cardíaco encontra-se mais para o interior do tórax e pode estar, lateralmente ao ponto onde se percebe o ictus cordis, cerca de meio centímetro.

O coração é um órgão relativamente móvel no interior da caixa torácica. Encontra-se fixo ao mediastino pela inserção das veias pulmonares no átrio esquerdo, sendo envolvido pelo pericárdio, que limita, parcialmente, a amplitude de sua movimentação. Essas características anatômicas garantem certo grau de mobilidade no interior da caixa torácica, mobilidade que é garantida pela conformação anatômica da massa muscular, ventricular, porção do coração que menor restrição experimenta à movimentação. São relações anatômicas, que permitem ao coração, principalmente aos ventrículos, movimentos de rotação e translação ao longo do eixo base-ápice, que são responsáveis pela aproximação do coração da parede torácica durante a sístole ventricular.

De importância fundamental para o entendimento da fisiologia do ictus cordis é o conhecimento de que, na primeira fase da sístole do ciclo cardíaco, que se inicia logo após o fechamento das valvas mitral e tricúspide (cujo correspondente auscultatório é a primeira bulha cardíaca), pode-se documentar um período em que o coração se contrai, aumentando a pressão no interior do ventrículo, sem que ocorra alteração de volume, pois a valva aórtica ainda não se abriu. É a fase que recebe o nome de contração isovolumétrica. Durante essa fase, o movimento de rotação e translação dos ventrículos faz com que o coração se aproxime da parede torácica e logo após, inicia-se a ejeção ventricular, com a abertura da valva aórtica, responsável por diminuição do volume ventricular e afastamento do coração da parede torácica.

O ictus pode ser percebido em cerca de $25 \%$ dos pacientes. Ele pode ser observado com o paciente em posição supina, em decúbito dorsal ou lateral esquerdo. Notadamente, em condições fisiológicas, observa-se variação das características descritas a seguir, na dependência da posição do paciente, e, portanto, quando se descreve o ictus no exame físico, deve-se, obrigatoriamente, anotar em qual posição foi realizada a observação. O decúbito lateral esquerdo aproxima o coração da parede torácica, tornando as características do ictus cordis mais pronunciadas, sendo, portanto, um recurso importante com aqueles pacientes com os quais não é possível observação ou palpação em decúbito dorsal.
Independentemente da posição em que se pesquisa o ictus, o médico deve colocar-se à direita do paciente, com seu campo visual voltado para a localização onde ele é mais comumente detectado, tendo-se o cuidado de procurar condições ideais de iluminação.

As características do ictus cordis, que devem ser examinadas são: localização, extensão, duração, intensidade, forma, ritmo e componentes acessórios. Essas características serão sempre identificadas, inicialmente, na posição supina e, quando sofrerem influência da posição, também na posição específica, sob avaliação.

\section{1- Localização}

Como conseqüência da relativa mobilidade do coração no interior da caixa torácica, a posição do paciente pode influenciar na localização do ictus.

No decúbito dorsal, ele pode ser percebido no quarto ou no quinto espaço intercostal esquerdo, na linha hemiclavicular ou medialmente à mesma. (Figura 1 A). Já no decúbito lateral esquerdo, pode sofrer um deslocamento de cerca de dois centímetros, lateralmente, em direção à axila. (Figura $1 \mathrm{~B}$ ).

A percepção da mobilidade do ictus, com a mudança de posição, é uma observação importante. A ausência de mobilidade do ictus, em direção à axila, quando o paciente é posicionado em decúbito lateral esquerdo, pode sugerir entidades nosológicas específicas, como a pericardite constrictiva.

A determinação adequada da localização do ictus pode ser extremamente dificultada em algumas condições clínicas, especialmente em doenças pulmonares, como o enfisema pulmonar, em que ocorre hiperexpansão do tórax e interposição de tecido pulmonar entre o coração e a parede torácica. Em pacientes, nos quais se observa aumento da extensão do ictus, como ocorre em portadores de miocardiopatia, dilatada ou de cardiopatia chagásica, crônica, a localização precisa pode ser impossível.

Além da presença do ictus cordis, é possível identificar a presença de outras impulsividades precordiais, cujas descrições também são importantes pelo valor diagnóstico que encerram. Dentre elas, destacam-se a pulsação epigástrica e paraesternal, esquerda, cuja identificação está relacionada a aumento da pressão e/ou do volume do ventrículo direito. Essas regiões de impulsividade precordial ocorrem em situações clínicas em que haja acometimento de cavidades direitas, decorrentes de um processo fisiopatológico, primário, do pulmão, como ocorre no cor 
pulmonale, ou secundárias a um acometimento de câmaras esquerdas, como nas miocardiopatias de padrão dilatado, nas valvopatias e na doença isquêmica do coração. Considerando-se a pouca expressão auscultatória de condições clínicas, que acometem cavidades cardíacas direitas, a percepção desses sinais pode contribuir para a adequada caracterização clínica desse envolvimento.

\section{2- Extensão}

Geralmente, o ictus cordis ocupa uma extensão em torno de duas polpas digitais (cerca de 2 a $2,5 \mathrm{~cm}$ ), ocupando, no máximo, um ou dois espaços intercostais. (Figura 1 C.) Trata-se, também, de uma característica que sofre influência postural. Ao assumir o decúbito lateral esquerdo, a extensão pode aumentar para cerca de três polpas digitais ou 3 a $3,5 \mathrm{~cm}$, devido à maior proximidade do ventrículo esquerdo em relação à parede torácica.

Cardiopatias que determinam dilatações importantes do ventrículo esquerdo implicam em aumento da extensão do ictus, podendo-se citar, como exemplo, as miocardiopatias de padrão dilatado e a cardiopatia chagásica crônica.

\section{3- Duração}

Conforme ressaltado anteriormente, a percepção do ictus está relacionada ao contato da porção anterior do coração com a parede torácica durante a fase de contração isovolumétrica do ciclo cardíaco. Com o esvaziamento dos ventrículos, durante a ejeção ventricular, o coração se afasta da parede e o ictus deixa de ser percebido. Depreende-se, assim, que o ictus é um fenômeno que se manifesta precocemente na sístole e deve ser simultâneo, ou mesmo, preceder a percepção do pulso carotídeo (expressão da ejeção ventricular ao exame físico).

Enquanto, em indivíduos normais, observa-se a presença do ictus cordis simultaneamente à palpação do pulso arterial carotídeo (Figura $1 \mathrm{~A} \mathrm{e} \mathrm{B),} \mathrm{em} \mathrm{paci-}$ entes com comprometimento da ejeção ventricular, como ocorre em portadores de estenose valvar aórtica significativa ou miocardiopatias de grau avançado, a ejeção ventricular é prolongada e o esvaziamento ventricular encontra-se retardado, prolongando o contato do mesmo com a parede torácica. No exame físico, isso se expressa pela percepção do ictus muito após o desaparecimento do pulso arterial carotídeo.

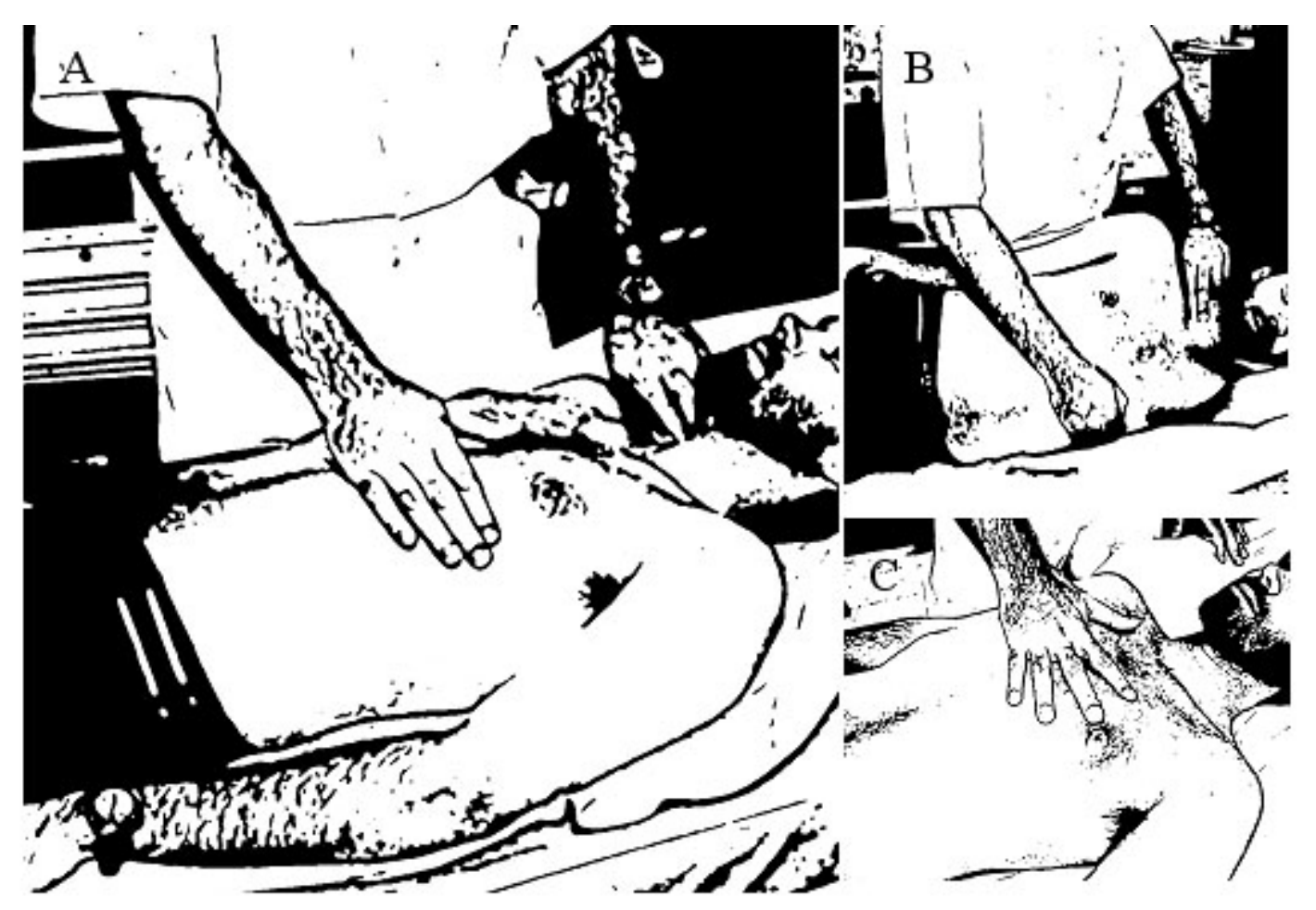

Figura 1: Semiotécnica da avaliação do ictus cordis. A) palpação em decúbito dorsal; B) palpação em decúbito lateral esquerdo; C) localização do ictus cordis, contando-se os espaços intercostais a partir do segundo espaço (ângulo de Louis). Observe que, em A e B, a palpação do ictus é simultânea com o pulso carotídeo. 


\section{4- Intensidade}

A observação sistemática do ictus permite identificar pacientes que apresentam impulsividade aumentada ou diminuída. O principiante, geralmente, associa tal percepção como uma característica para determinar o estado contrátil cardíaco. Entretanto, a intensidade da impulsão do ictus não guarda relação direta com a contratilidade miocárdica. Pacientes com miocardiopatias de padrão dilatado podem apresentar impulsividade aumentada devido ao aumento da extensão do ictus, sem que isso traduza aumento da força contrátil do coração.

\section{5- Forma}

Descrições do ictus cordis como globoso ou cupuliforme são comuns na literatura. Entende-se, como forma, uma característica composta, que leva em consideração a duração e a extensão anteriormente descritas.

Aqueles pacientes que apresentam aumento da extensão e da duração do ictus, geralmente associadas a deslocamento lateral e rebaixamento, apresentam ictus globoso. Pacientes hipertensos ou apresentando estenose aórtica grave, geralmente, apresentam extensão e localização preservadas, mas duração aumentada, características que se apresentam no ictus impulsivo.

\section{6- Ritmo}

O exame do ictus pode, também, fornecer informações relativas ao ritmo cardíaco do paciente. A palpação simultânea com o pulso arterial carotídeo deve ser novamente executada para a adequada avaliação de tal característica.

Assim, distúrbios do ritmo, como fibrilação atrial ou extrassistolia, podem ser adequadamente identificados, o que pode influenciar outras características descritas. Por exemplo, na fibrilação atrial, que se associa a enchimento variável do ventrículo esquerdo, a intensidade e a duração do ictus podem apresentar variações, batimento a batimento.

\section{7- Componentes Acessórios}

Além da percepção do componente principal do ictus, a inspeção e a palpação cuidadosas, associadas à palpação do pulso arterial carotídeo ou à ausculta cardíaca, podem identificar componentes acessórios. Dentre os componentes acessórios, os dois mais comumente encontrados são os correspondentes à terceira e quarta bulhas. São de importância clínica, inequívoca e, algumas vezes, são palpáveis, mas não audíveis.

A correta identificação desses componentes pode ser obtida, de maneira muito mais fácil, pela palpação simultânea do pulso carotídeo. Caso o componente acessório, percebido, geralmente reconhecido por ser de menor amplitude que o ictus propriamente dito, preceder o pulso carotídeo, trata-se do correspondente palpatório da quarta bulha cardíaca. Caso esse componente acessório suceda o pulso carotídeo, trata-se de uma terceira bulha cardíaca.

Em resumo, a avaliação do ictus é de suma importância na semiotécnica cardiológica, pois é a única abordagem do exame físico que oferece informações sobre a presença de cardiomegalia. A identificação de um ictus cordis, deslocado para a esquerda, rebaixado, estendendo-se por três ou mais espaços intercostais e com duração prolongada, é o indicativo de um processo fisiopatológico, determinante de cardiomegalia. A identificação de sinais de cardiomegalia representa um achado importante no exame físico, pois, muitas vezes, está associada à depressão da função sistólica do coração, o que implica em aumento de mortalidade e morbidade dos pacientes com tais sinais.

\section{3- PERFUSÃo PERIFÉRICA}

A avaliação da perfusão periférica, durante o exame físico, é extremamente valiosa para determinação da presença de débito cardíaco, adequado às necessidades metabólicas do organismo. $\mathrm{O}$ exame do leito vascular das extremidades é de fácil acesso e execução, além de permitir reavaliações repetidas durante intervenções terapêuticas.

A investigação clínica da perfusão periférica pode ser efetuada com base na análise de várias características: temperatura, coloração e grau de enchimento das extremidades. Deve-se ter sempre presente que alterações da magnitude da perfusão periférica não são as únicas causas de modificações dessas variáveis, devendo-se considerar, também, a possível influência de estímulos externos sobre elas. Assim, por exemplo, caso o paciente tenha tido contato com água fria ou a temperatura ambiente esteja muito reduzida, a percepção tátil de extremidades frias e a observação de presença de cianose nesse local, provavelmente, pode ser explicada por reflexo de vasoconstrição periférica, visando à preservação de calor, ao invés de representar diminuição da perfusão periférica, decorrente de processo patológico. 
A avaliação da coloração, à inspeção, pode ser muito prejudicada em pacientes anêmicos ou de pele escura. Por outro lado, a compressão do leito vascular distal pode sensibilizar a percepção da alteração de coloração.

O enchimento do leito vascular das extremidades é avaliado com a compressão da polpa de um ou mais dígitos, o que ocasiona um esvaziamento da microvasculatura daquela região. Com a liberação da compressão, o leito ungueal se torna esbranquiçado e vai, gradativamente, readquirindo a coloração normal da pele circunvizinha, à medida que o leito microvascular é novamente preenchido com sangue. Em indivíduos com perfusão periférica, normal, o enchimento é rápido, da ordem de dois a três segundos. Nos casos de redução da perfusão, o enchimento se torna cada vez mais lento, mantendo uma correlação direta com a gravidade do quadro. A correta avaliação do grau de redução, na velocidade de enchimento do leito vascular, se faz através da comparação com o enchimento observado no próprio examinador.

A avaliação da temperatura, coloração e enchimento vascular das extremidades é de suma importância para a diferenciação das causas do comprometimento da perfusão tecidual. Assim, por exemplo, no contexto do choque cardiogênico, pode-se observar extremidades frias, cianóticas e com enchimento lentificado, enquanto, no choque séptico, elas podem ser quentes e coradas, ainda que apresentem, também, enchimento vascular, periférico, prejudicado.

\section{4- PULSOS ARTERIAIS}

Pulso, no contexto biológico, aplicado ao sistema cardiovascular, é definido como qualquer flutuação periódica no sistema, causada pelo coração. Quando o sangue é ejetado para o interior do sistema arterial, são geradas alterações no fluxo, na pressão e nas dimensões dos vasos. Embora qualquer um dos três fatores apresente variações pulsáteis durante o ciclo cardíaco, o pulso, tal como é avaliado no exame físico, é decorrente, principalmente, de alterações da pressão intravascular. Apesar disso, a magnitude do pulso não é diretamente correlacionada com a pressão intravascular. A percepção da amplitude do pulso depende, além da magnitude de pressão intravascular, das dimensões da artéria sob avaliação e da pressão exercida pelos dedos do examinador. A sensação de um pulso de baixa amplitude pode resultar tanto de níveis reduzidos de pressão arterial sistêmica como representar um pulso de amplitude normal, avaliado, em uma artéria muito estreita.

Um outro aspecto da fisiologia de propagação de pulso arterial, no sistema cardiovascular, é fundamental para a adequada aplicação dessa técnica de investigação clínica. Durante a ejeção ventricular, a parede da aorta se distende e gera uma onda que se propaga através de todo o sistema arterial até o nível das arteríolas. Neste local, devido à acentuada redução do diâmetro dos vasos, existe um aumento importante da resistência oferecida à propagação do fenômeno. É o ponto em que ocorre uma reflexão da propagação do pulso, ou seja, é gerada uma onda de pulso de sentido oposto (da periferia para o centro). A propagação dessa onda até as arteríolas e o retorno de seu componente retrógrado ocorrem muito rapidamente, sendo possível que, dentro do mesmo ciclo cardíaco, o fenômeno se propague até a periferia e retorne aos vasos mais calibrosos. Assim, um fator adicional passa a influenciar a nossa percepção das características do pulso arterial, uma vez que ela passa a representar a somatória da onda que se propagou em direção à periferia e da correspondente reflexão. Apesar de sentidos opostos de propagação do fluxo, as ondas de pulso (a original e a refletida) são percebidas no mesmo sentido pelo clínico. (Figura 2.) Assim, podese depreender que a percepção do pulso é influenciada pela velocidade de propagação dessas ondas, que, por sua vez, dependem das características estruturais do sistema arterial. Deste modo, sistemas arteriais mais rígidos, como aqueles encontrados em idosos, permitem uma propagação mais rápida, enquanto que sistemas mais complacentes, como ocorre em jovens, favorecem uma propagação mais lenta dessas ondas.

Uma outra característica que influencia a percepção do pulso, levando em consideração o fenômeno de reflexão, é o sítio onde o pulso é avaliado. $\mathrm{Na}$ dependência da distância a ser percorrida pelo pulso, pode ocorrer que a onda de reflexão interfira com a onda que é gerada durante a ejeção ventricular, de maneira diversa. Em pequenas distâncias, dependendo do ângulo de reflexão, em relação à onda original, ela poderá reduzir a magnitude do pulso, além de modificar sua forma. Entretanto, ao percorrer distâncias maiores, como ocorre nos membros inferiores, o maior tempo para a propagação da onda retrógrada pode determinar que ela venha a somar-se com o pulso gerado no ciclo cardíaco, subseqüente, aumentando a amplitude do pulso nos membros inferiores. Então, se 


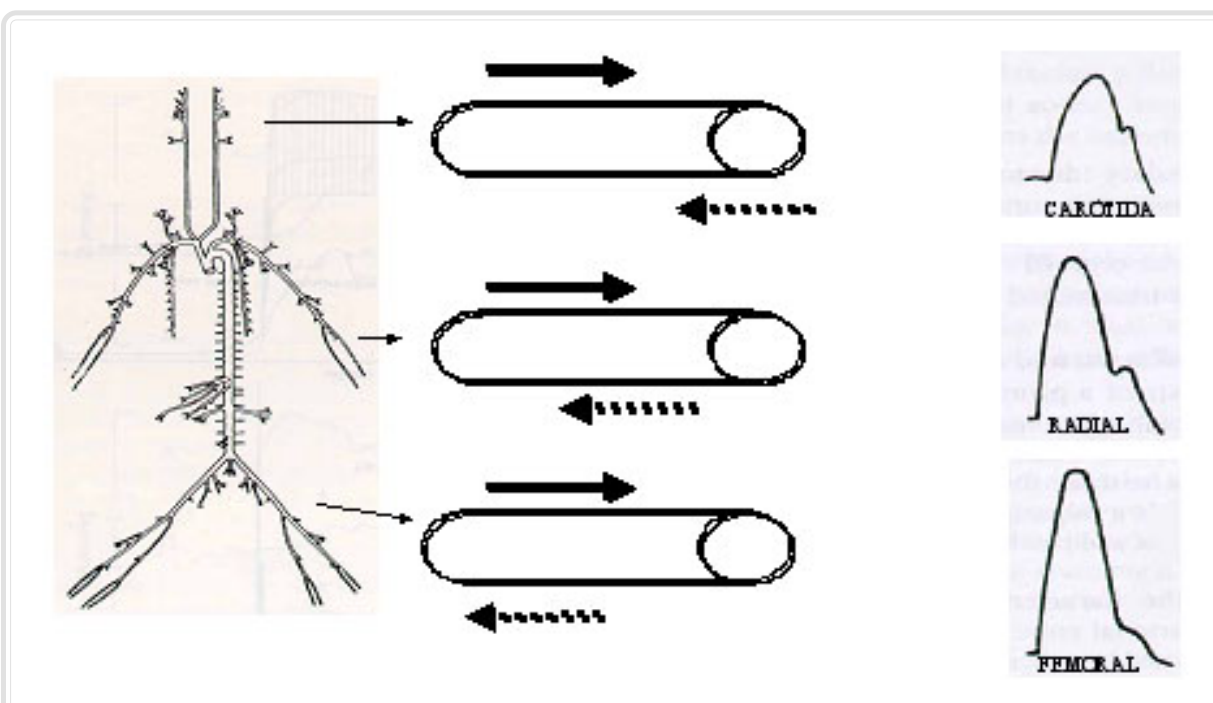

Figura 2: Pulsos Arteriais

Ondas de pressão, obtidas por estudo hemodinâmico invasivo, em diversos pontos do sistema cardiovascular (carótidas, radial e femoral). As setas, cheias representam a onda de pulso anterógrada (centro-periferia) e a seta tracejada, a onda de pulso retrógrada (periferia-centro). Observe que, na carótida, devido à proximidade do coração, a onda retrógrada é muito posterior à onda anterógrada, enquanto que o inverso ocorre na artéria femoral, onde a onda anterógrada e a retrógrada são praticamente simultâneas. Tal mecanismo é responsável pelo aumento da amplitude do pulso arterial nos locais mais distantes do coração.

so com a ausculta cardíaca possibilita verificar a concomitância entre o batimento cardíaco e a ocorrência do pulso. Normalmente, a cada batimento, deve-se detectar o pulso arterial, correspondente. A não ocorrência dessa concomitância, ou seja, quando nem todo batimento auscultado tem seu correspondente palpável, indica que a contração imediatamente precedente não teve intensidade suficiente para abrir a valva aórtica e gerar o pulso correspondente.

- Localização - A avaliação dos pulsos deve ser realizada em todos os locais onde eles podem ser palpados: carotídeo, temporal, braquial, radial, ulnar, abdominal, femoral,

o objetivo da avaliação do pulso for determinar seu contorno ou sua velocidade de inscrição, o exame deve ser realizado em locais mais proximais do sistema arterial, como, por exemplo, o pulso carotídeo, cuja amplitude e forma aproximam-se mais das características do pulso aórtico.

Frente ao exposto, as características básicas, que devem ser investigadas na avaliação dos pulsos arteriais, são as que vêm a seguir:

- Freqüência - alterações da freqüência cardíaca podem ser facilmente determinadas pela palpação do pulso em qualquer sítio; é importante ressaltar que, na presença de alterações do ritmo cardíaco, a freqüência será mais precisamente determinada, aumentando-se o tempo de observação.

- Ritmo - deve-se avaliar se o ritmo é regular ou irregular. Quando irregular, é possível, com a prática, identificar algumas características que sugiram a presença de alguns distúrbios do ritmo cardíaco, específicos, como a fibrilação atrial ou extra-sístolia. É importante registrar que essa técnica tem especificidade limitada para estabelecer o diagnóstico de arritmias, embora possa oferecer informações relevantes para isso. A avaliação concomitante, do pul- poplíteo, tibial posterior e pedioso.

- Simetria - Percepção da amplitude dos pulsos palpáveis em comparação com o mesmo pulso contralateral. Tal análise oferece subsídios para o diagnóstico de situações como obstrução arterial, crônica, de membros inferiores ou de outras doenças vasculares, periféricas.

- Formato - O formato do pulso expressa a análise do seu contorno. Do ponto de vista clínico, embora uma grande variedade de formatos seja descrita com estudos invasivos das ondas de pulso, essas alterações são de difícil percepção e exigem muita prática. Na Tabela I, estão exemplificados alguns padrões de pulsos arteriais mais freqüentes, com o objetivo primário de demonstrar como a caracterização do formato do pulso pode ser útil para avaliação de algumas doenças. Para a distinção entre os diversos pulsos de duplo pico, a caracterização do momento do ciclo em que as ondas ocorrem é fundamental. É importante ressaltar que devem ser pesquisados em pulsos proximais, como o pulso carotídeo.

- Amplitude - A amplitude do pulso pode ser influenciada por vários fatores, como ressaltado acima. Sua 
percepção pode ser facilitada, quando se examinam pulsos de localização mais distal no sistema arterial. Quanto à amplitude, os pulsos arteriais podem ser classificados como de amplitude normal, aumentada ou reduzida. É implícita, nessa classificação, que o observador deverá definir, a gradação de amplitude segundo uma escala individual, que depende, fundamentalmente, da experiência acumulada. Deste modo, a avaliação tem componentes bastante subjetivos, mas que não diminuem sua importância clínica. Além disso, o pulso arterial pode apresentar amplitude variável, batimento a batimento. Dois ti- pos de pulso de amplitude variável adquirem importância especial e estão ressaltados na Tabela II.

É muito importante salientar que a análise do conjunto dessas características facilita o aprendizado e a caracterização dos diferentes tipos de pulso. Assim, por exemplo, embora, por motivos didáticos, seja realizada uma classificação dos pulsos de acordo com uma característica isolada, como exposto nas Tabelas I e II, em algumas situações, a análise de conjunto propicia uma melhor caracterização. Dois exemplos podem ser citados: o pulso bisferiens e o pulso tardus e parvus.

Tabela I: Classificação e características clínicas dos pulsos arteriais quanto ao formato.

\begin{tabular}{|c|c|c|c|}
\hline & Formato & Características Clínicas & Exemplo \\
\hline $\begin{array}{l}\mathrm{P} \\
\mathrm{u} \\
1\end{array}$ & & $\begin{array}{l}\text { PULSO BISFERIENS } \\
\text { - Pulso amplo, com dois componentes perceptíveis } \\
\text { durante a sístole. } \\
\text { - Sinonímia - Pulso de Corrigan; Pulso em martelo } \\
\text { d'água. } \\
\text { - Geralmente, acompanhado de outros sinais } \\
\text { periféricos de insuficiência aórtica. }\end{array}$ & - Insuficiência Aórtica \\
\hline $\begin{array}{l}\mathrm{D} \\
\mathrm{u} \\
\mathrm{p} \\
\mathrm{l} \\
\mathrm{o}\end{array}$ & $\begin{array}{l}\text { 81 } \\
1\end{array}$ & $\begin{array}{l}\text { PULSO BÍFIDO } \\
\text { - Sinonímia - "Pico e Domo" } \\
\text { - Pulso amplo, com dois componentes sistólicos. } \\
\text { - O primeiro componente é decorrente da fase de } \\
\text { ejeção rápida, sendo limitado no momento em } \\
\text { que se estabelece a obstrução dinâmica aofluxo } \\
\text { sangüíneo. Segue-se o segundo componente, de } \\
\text { ejeção mais lenta, com configuração de um domo. } \\
\text { - Geralmente, de difícil detecção à beira do leito. } \\
\text { - Quando presente, implica em gravidade. }\end{array}$ & $\begin{array}{l}\text { - Miocardiopatia } \\
\text { Hipertrófica }\end{array}$ \\
\hline $\begin{array}{l}\mathrm{P} \\
\mathrm{i} \\
\mathrm{c} \\
\mathrm{o}\end{array}$ & & $\begin{array}{l}\text { PULSO DICRÓTICO } \\
\text { - Raro. } \\
\text { - Caracteristicamente apresenta um pico na diástole. } \\
\text { - Pode ser diferenciado dos anteriores por maior } \\
\text { intervalo entre os picos. } \\
\text { - Não ocorre acima de } 45 \text { anos. }\end{array}$ & $\begin{array}{l}\text { - Estados de Baixo Débito } \\
\text { - Tamponamento Cardíaco } \\
\text { - Insuficiência Cardíaca } \\
\text { Congestiva }\end{array}$ \\
\hline
\end{tabular}


Tabela II: Classificação e características clínicas dos pulsos arteriais quanto à variação da amplitude

\begin{tabular}{|c|c|c|}
\hline Tipo & Características & Exemplo \\
\hline Pulso Alternante & $\begin{array}{l}\text { - alterna intensidade maior e menor com a mesma freqüência } \\
\text { - mais perceptível no pulso radial } \\
\text { - um dos sinais mais precoces de disfunção ventricular } \\
\text { - alteração da intensidade das bulhas e dos sopros } \\
\text { - sensibilizado pela posição sentada ou em pé } \\
\text { - quanto mais intensos os achados, maior a disfunção }\end{array}$ & $\begin{array}{l}\text { - insuficiência cardíaca } \\
\text { congestiva }\end{array}$ \\
\hline Pulso Paradoxal & $\begin{array}{l}\text { - sinonímia - Pulso de Kussmaul } \\
\text { - diminui de intensidade ou desaparece com a inspiração } \\
\text { - denominação errônea - na realidade é uma exacerbação de } \\
\text { um fenômeno normal (queda da pressão com a inspiração) } \\
\text { - melhor pesquisado através da aferição da pressão arterial } \\
\text { (vide capítulo sobre Verificação da Pressão Arterial) }\end{array}$ & $\begin{array}{l}\text { - tamponamento cardíaco } \\
\text { - pericardite constritiva } \\
\cdot \text { asma severa ou DPOC }\end{array}$ \\
\hline Pulso parvus e tardus & $\begin{array}{l}\text { - sinonímia - Pulso Anacrótico } \\
\text { - caracterizado por amplitude diminuída e retardo da } \\
\text { elevação do pulso, que se encontra lentificado; } \\
\text { - pode ser mascarado pelas alterações decorrentes da idade; } \\
\text { - quando presente, implica em severidade da lesão; } \\
\text { · é um sinal de desenvolvimento tardio. }\end{array}$ & - estenose aórtica \\
\hline
\end{tabular}

O pulso bisferiens é mostrado, na Tabela I, como um dos três tipos de pulso de duplo pico. A alteração de seu contorno é uma característica fundamental para sua caracterização. Porém outras características devem ser ressaltadas: é um pulso de elevação e descenso rápidos, decorrentes da grande quantidade de volume ejetado e do volume regurgitante, respectivamente, na insuficiência aórtica, grave; e possui amplitude aumentada, decorrente, também, do grande volume ejetado. Essas alterações podem ser percebidas ao longo de todo o sistema arterial.

O pulso parvus e tardus é encontrado na estenose aórtica e está ilustrado na Tabela II como exemplo de pulso caracterizado por alteração de amplitude. A baixa amplitude é característica desse tipo de pulso, mas ele também é caracterizado por uma elevação lenta da sua porção ascendente, o que ocasiona que ele seja percebido tardiamente na sístole, durante a palpação. Essas modificações de amplitude (parvus) e de localização no ciclo (tardus) são características fundamentais dessa alteração, e são freqüentemente mascaradas por perda da elasticidade do sistema arterial, como aquelas decorrentes do envelhecimento. Embora tais alterações dificultem sua percepção e sejam um sinal tardio da estenose aórtica, implicam sempre, em severidade do quadro.

\section{5- PULSOS VENOSOS}

Devido ao fato de o sistema venoso estar submetido a um regime de pressão muito menor, comparado ao sistema arterial, a avaliação do pulso venoso é realizada quase que exclusivamente através da inspeção. Significa dizer que o pulso venoso é visível, mas, na enorme maioria das vezes, não é palpável, o que facilita na sua distinção do pulso carotídeo, que pode ser visível normalmente. Também decorrente dessa característica é o fato de se perceber o pulso venoso apenas próximo ao coração, na região cervical. Além de habitualmente não ser palpável, o pulso venoso pode diferenciar-se de um pulso arterial por apresentar, em cada ciclo cardíaco, mais de uma oscilação visível à inspeção, enquanto apenas uma é identificada no pulso arterial.

A avaliação clínica do pulso venoso adquire importância, no exame físico, para dois objetivos: caracterização da pressão venosa central e determinação de algumas doenças específicas.

\section{1- Estimativa da pressão venosa central}

A avaliação não invasiva, da pressão venosa central oferece informações fisiopatológicas importantes na investigação clínica de pacientes que apresen- 
tam doenças cardiovasculares ou pulmonares que estão associadas, na sua história natural, à elevação da pressão venosa central. Incluem-se, entre elas, diferentes entidades nosológicas, que cursam com a insuficiência cardíaca e as doenças pulmonares, que acabam por promover sobrecarga crônica, de cavidades cardíacas direitas. De modo geral, quanto maior a elevação da pressão venosa central, maior a gravidade das repercussões funcionais.

A estimativa da pressão venosa central pode ser realizada de um modo muito simples. Para sua compreensão é importante uma recordação das relações anatômicas do sistema venoso na região cervical. Observe a Figura 3. Nela, pode ser observado que a veia jugular, interna, direita comunica-se com o átrio direito quase em linha reta através da veia cava, superior, enquanto que o mesmo não ocorre com a veia jugular, interna, esquerda, devido à interposição da veia inominada. Dessa relação anatômica, pode-se compreender que as pressões venosas, centrais, geradas em câmaras cardíacas, direitas, serão transmitidas diretamente para a veia jugular, interna, direita.

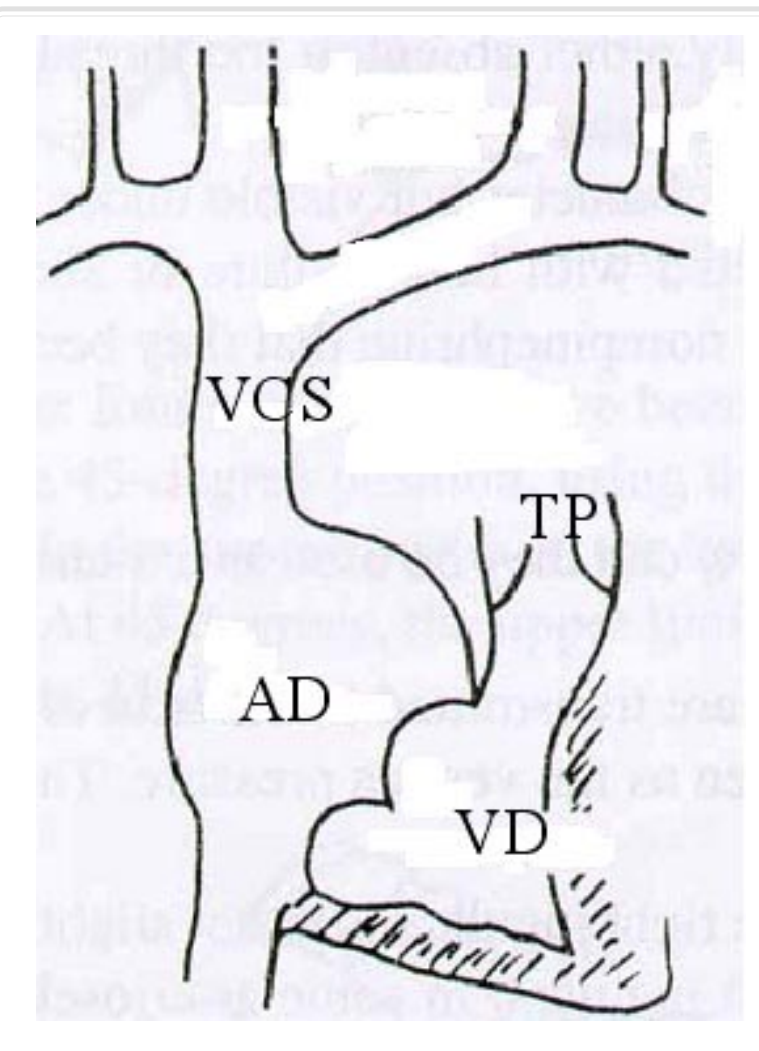

Figura 3 - Sistema Venoso. VCS - Veia Cava Superior; AD - Átrio Direito; VD - Ventrículo Direito; TP - Tronco da Artéria Pulmonar
A transmissão é facilitada, ainda mais, pelo fato de não existirem valvas nas veias intratorácicas.

Pelo exposto acima, a técnica para avaliação da pressão venosa, central baseia-se na transmissão da pressão através da coluna sangüínea até a veia jugular interna, direita. Essa transmissão de pressão gera o pulso venoso, que pode ser perceptível em todas as veias jugulares (interna e externa; direita e esquerda), porém, com melhores condições anatômicas de transmissão e com menor atenuação, na veia jugular, interna, direita. A altura em que se observa o pulso, no pescoço, guarda correspondência direta com o valor da pressão; quanto maior a pressão, mais elevado o nível de pulsação venosa, aproximando-se da mandíbula (Figura 4A).

Devido à correlação direta entre a altura em que é identificado o pulso e a pressão venosa, o pulso pode ser utilizado, de maneira relativamente simples, como um "aparelho de pressão" que utiliza uma coluna de água, e basta realizar a calibração do sistema para que se obtenha a pressão. A calibração se baseia no conhecimento de que o átrio direito fica localizado cerca de $5 \mathrm{~cm}$ abaixo da junção entre o corpo do esterno e o manúbrio - Ângulo de Louis. (Figura 4 B, C e D.) Com tal conhecimento, a obtenção da pressão venosa, central pode ser realizada somando-se $5 \mathrm{~cm}$ à distância entre o local onde o pulso é percebido e a junção do corpo com o manúbrio do esterno.

Do ponto de vista semiológico, deve-se colocar o paciente em posição confortável, com a cabeça relaxada e voltada para o lado esquerdo. O uso de iluminação tangencial ao pescoço pode sensibilizar a percepção do pulso venoso. A cama do paciente deve ser colocada numa inclinação que permita perceber a pulsação venosa. Em pessoas sem alterações patológicas, geralmente, isso implica em um ângulo de $45^{\circ}$ (Figura 4C), pois ângulos menores elevam o pulso para o interior do crânio e ângulos maiores trazem o pulso para o interior do tórax, tornando-o não perceptível em ambas as situações. Não se pode esquecer que a medida da altura sempre deve ser realizada na vertical. Em situações patológicas, no entanto, mesmo com o paciente sentado ou em pé, caso a pressão venosa central esteja elevada, o pulso será perceptível e a regra para a aferição da pressão persiste a mesma. Devese lembrar, ainda, que, na maioria das situações clínicas, o médico não dispõe de um leito que possa ser adequadamente angulado para essa avaliação. Assim, considerando que o objetivo principal dessa medida é 


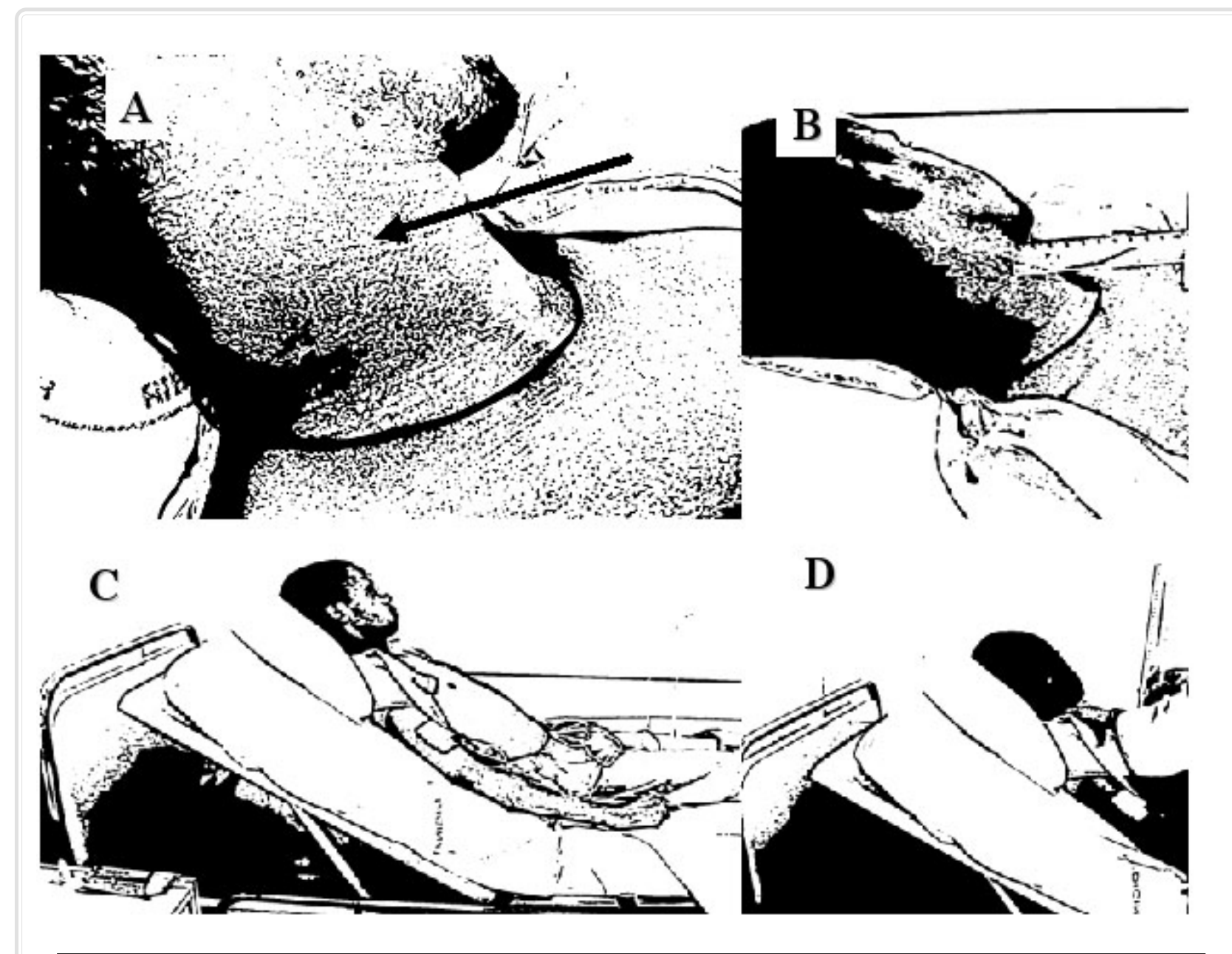

Figura 4 - Pulso Venoso. Vide texto.

identificar situações clínicas com elevação da pressão venosa, a avaliação realizada com o paciente sentado parece ser a mais adequada.

Deve-se salientar que tal técnica é uma estimativa da pressão venosa, central. Estudos que compararam as pressões obtidas dessa maneira com métodos mais acurados, como a Doppler ecocardiografia ou mesmo com técnicas invasivas e de mensuração direta, como o estudo hemodinâmico, não encontraram correlação elevada. No entanto, pela facilidade de se obter o dado à beira do leito, essa técnica persiste sendo empregada na prática clínica, diária.

A amplitude e a localização do pulso venoso sofrem alteração na dependência da fase do ciclo respiratório. Durante a inspiração, devido à queda da pressão intratorácica, observa-se diminuição da amplitude do pulso e este tende a se aproximar da base do pescoço, ou mesmo deixar de ser visível, por ter se deslocado para o interior da cavidade torácica. Em situações patológicas, em que o enchimento do ventrículo direito encontra-se prejudicado, pode-se observar uma situação paradoxal, na qual, durante a inspiração, notase um ingurgitamento das veias cervicais, com aumento da amplitude do pulso e deslocamento em direção à mandíbula. Tal situação recebe o nome de Sinal de Kussmaul, que pode ser encontrado em várias situações, sendo a pericardite constritiva a mais característica.

Em pacientes com insuficiência cardíaca, em uso de diuréticos, a avaliação do pulso venoso pode levar à falsa impressão de que a pressão venosa central se encontra baixa ou dentro dos padrões da nor- 
malidade. Então, está indicado o uso do chamado "reflexo abdominojugular". Trata-se de uma manobra onde se realiza uma compressão abdominal, com a mão espalmada, colocada sobre o andar superior do abdome. A compressão deve ser lenta e gradual, não causando desconforto ao paciente. Ao se realizar a compressão, deve-se observar atentamente o pulso venoso; caso se observe uma elevação de cerca de três centímetros em relação ao valor documentado durante a situação basal, persistente durante todo o período da compressão, evidencia-se que a pressão venosa está elevada.

\section{Determinação de entidades nosológicas especí- ficas}

A identificação de entidades nosológicas, específicas, através do pulso venoso, baseia-se no formato de sua onda. Na Figura 5, está representada a curva de pressão venosa central obtida durante cateterismo cardíaco, correlacionada com o eletrocardiograma (na parte superior da figura) e com as bulhas cardíacas (na parte inferior da figura). Imediatamente antes da sístole ventricular, na porção final da diástole, ocorre a sístole atrial, ocasionando a onda A. Com a contração do ventrículo, no início da sístole, ocorre a ejeção do ventrículo, ocasionando o pulso carotídeo. O pulso arterial carotídeo, devido à sua estreita relação com o sistema jugular, é transmitido para o sistema venoso, ocasionando a onda C. A contração ventricular ocasiona a descida dos átrios em direção ao ápice do ventrículo e uma queda da pressão venosa central (Descenso X'). Com o enchimento do átrio direito, a pressão venosa central começa a se elevar e é transmitida para as jugulares, sendo percebida como onda V. Com a abertura da valva tricúspide e o início do enchimento ventricular, na fase inicial da diástole, a pressão venosa central volta a cair, sendo expressa na curva de pressão através do Descenso Y.

À beira do leito, no entanto, a percepção das três ondas e dos dois descensos descritos é limitada.

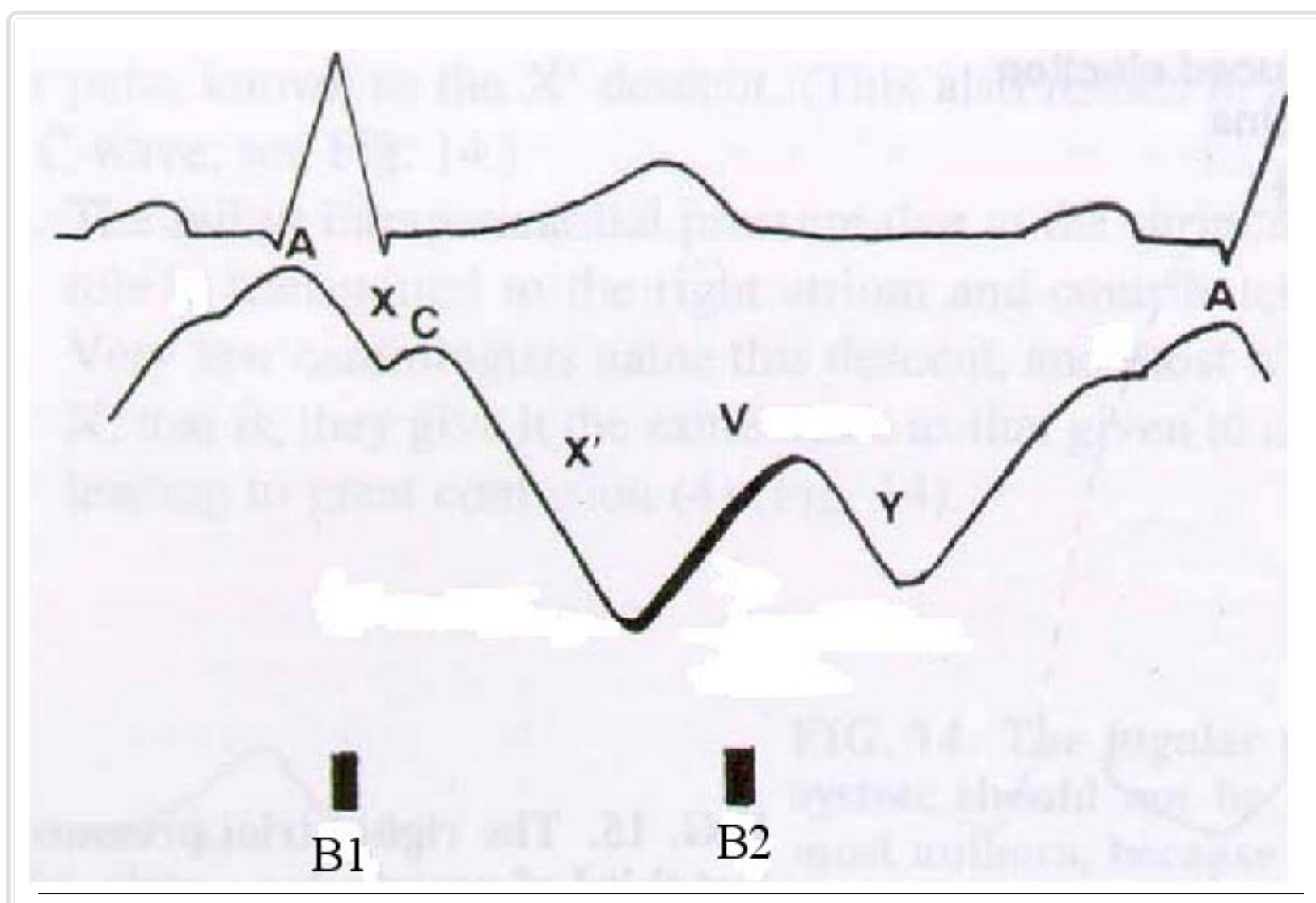

Figura 5 - Curva de Pressão Venosa. Vide texto 
Na grande maioria dos casos, o que se observa, com nitidez, são os dois descensos, conferindo ao pulso venoso um formato de duplo pico. O primeiro pico, representado pela fusão das ondas $\mathrm{A}$ e $\mathrm{C}$, é concomitante ao primeiro ruído cardíaco (B1) e o segundo pico (onda V) é concomitante ao segundo ruído cardíaco (B2). O formato, em duplo pico, do pulso venoso é mais uma característica que auxilia na sua distinção com o pulso arterial. Em condições fisiológicas, o pulso venoso apresenta dois componentes e não é palpável, enquanto o pulso arterial tem apenas um componente e é sempre palpável, mesmo que não seja visível.

Tais características são alteradas em diferentes condições clínicas e permitem sugerir alguns diagnósticos específicos. Dentre as inúmeras situações clínicas, merece destaque a insuficiência tricúspide. A insuficiência tricúspide é uma valvopatia comum e que, geralmente, acompanha uma grande variedade de cardiopatias. Está, geralmente, presente em situações em que há elevação da pressão arterial pulmonar. Suas características auscultatórias simulam aquelas da insuficiência mitral, diferenciando-se dessa condição por seus achados estarem mais restritos ao foco tricúspide e por seu sopro apresentar uma variação inspiratória de sua intensidade (Sinal de RiveroCarvallo). No entanto, devido ao menor regime de pressão nas cavidades direitas e pela concomitância de outras lesões valvares, a identificação de insuficiência tricúspide, exclusivamente através da ausculta, tem baixa especificidade. Alguns outros sinais, no exame físico, auxiliam na identificação da insuficiência tricúspide. Entre eles, destacam-se: a presença de pulsação paraesternal, esquerda, uma impulsividade precordial, similar à do ictus cordis, porém, com localização diferente; a presença de fígado pulsátil e, ainda, mediante a observação cuidadosa do pulso venoso e de seu formato.

Na vigência de insuficiência tricúspide, durante a contração ventricular, a pressão gerada pelo ventrículo direito é transmitida para o átrio e para o sistema venoso, proximal ao coração. Essa transmissão de pressão, durante a sístole ventricular, ocorre simultaneamente à onda $\mathrm{V}$, somando-se a ela, de modo a determinar uma onda de maior amplitude. No exame físico, observa-se que o segundo componente do pulso venoso é mais pronunciado. A concomitância da onda $\mathrm{V}$ mais pronunciada com o segundo ruído cardíaco auxilia na sua identificação.

Distúrbios do ritmo cardíaco, principalmente os distúrbios de condução atrioventriculares, totais (BAVT), podem ser identificados pela análise do pulso venoso. Manifesta-se, no exame físico, mediante variação na amplitude do pulso venoso. Considerar que, nessa condição clínica, ocorre dissociação entre as contrações atrial e a ventricular, de modo que elas não guardam entre si nenhuma relação temporal. Entretanto, em alguns momentos, pode acontecer de a contração atrial e a ventricular ocorrerem concomitantemente, de tal maneira que o átrio, nessa situação, se contrai contra uma valva tricúspide, fechada pela contração ventricular. Essa contração atrial irá gerar níveis mais elevados de pressão no átrio, o que resulta em maior transmissão de pressão para as veias proximais ao coração, gerando uma onda de pulsação venosa, no pescoço, mais ampla e que recebe a designação de onda A em canhão.

Situações clínicas em que o enchimento ventricular direito é comprometido também se associam a sinais que evidenciam o valor semiológico do pulso venoso. A restrição ao enchimento ventricular determina velocidades de enchimento maiores, traduzidas na curva de pulso venoso através de descensos $\mathrm{X}$ e $\mathrm{Y}$ mais pronunciados. As curvas de pressão venosa, quando isso ocorre, adquirem o aspecto das letras $\mathrm{W}$ ou $\mathrm{M}$ do alfabeto e assim são descritas na literatura. Pericardite constritiva, tamponamento cardíaco e as miocardiopatias restritivas são situações clínicas em que tais alterações podem ser observadas.

\section{6- PERCUSSÃo}

A percussão da região precordial do tórax é uma técnica de limitado valor semiológico. Ela não demonstra uma boa sensibilidade ou especificidade para estimar a área cardíaca, entretanto pode oferecer algumas informações de relevância clínica. Por um lado, a percussão do segundo espaço intercostal junto ao esterno, tanto à direita como à esquerda, permite sugerir a presença de dilatação do tronco da artéria pulmonar, quando o som claro pulmonar, habitualmente observado nesse local, é substituído pela observação de um som submaciço à percussão. Além disso, quando à percussão da região paraesternal esquerda, junto ao esterno, observa-se persistência de som claro, pulmonar, junto ao terceiro, quarto e quinto espaços intercostais, sugere-se a presença de ar, anteriormente ao coração, o que ocorre em doenças pulmonares, obstrutivas, especialmente no enfisema pulmonar. 
PAZIN-FILHO A; SCHMIDTA \& MACIEL BC. Cardiovascular examination: inspection, palpation and percussion. Medicina, Ribeirão Preto, v. 37: 227-239, july/dec. 2004.

ABSTRACT: The inspection and palpation of the physical examination of the cardiovascular system is emphatizated. The value of the analysis of the ictus cordis, periferic perfusion and arterial and venous pulses for the systematic evaluation of the several cardiopathies is reinforced.

UNITERMS: Cardiovascular System. Semiology. Pulse.

\section{REFERÊNCIAS}

1 - CHIZNER MA. The diagnosis of heart disease by clinical assessment alone. Curr Probl Cardiol 26: 285-380, 2001.

2 - VLACHOPOULOS C \& O'ROURKE M. Gênesis of the normal and abnormal arterial pulse. Curr Probl Cardiol 25: 297368, 2000.
3 - BRAUNWALD E; ZIPES DP \& LIBBY P. Heart disease: A textbook of cardiovascular medicine. $6^{\text {th }}$ ed. W. B. Saunders, Philadelphia, 2001. 